\title{
ALGUMAS CONSIDERAÇÕES ACERCA DO PODER EPISCOPAL NOS CENTROS URBANOS HISPÂNICOS - SÉCULO V AO VII
}

\author{
Leila Rodrigues da Silva*
}

\begin{abstract}
RESUMO
As atas do Concílio de Elvira, realizado em princípios do século IV, fornecem-nos indícios significativos do processo de expansão do cristianismo na Península Hispânica e sua estreita relação com os centros urbanos. Da leitura e análise de tais atas, uma atividade religiosa regular pode ser deduzida em 19 cidades cujos representantes participaram do referido concílio. Malgrado todos os reveses, passados três séculos, observamos a continuidade daquele processo. Deparamo-nos, então, com um alto clero extremamente influente, cujas ações norteiam grande parte do que restara da vitalidade urbana. Dessa forma, embora as invasões germânicas do século V tenham promovido uma considerável desorganização das instituições peninsulares, fenômeno, em um primeiro momento, especialmente palpável nas cidades, isso não significou a perda de influência do segmento eclesiástico sobre os rumos dos centros urbanos nos séculos seguintes. Com o posterior assentamento dos germanos e a organização de reinos, a atuação de uma elite clerical se destacou não apenas na esfera religiosa, mas também na civil. Interessanos, pois, neste artigo, a análise de alguns aspectos da inserção do episcopado hispânico nos núcleos urbanos nos séculos V-VII. Nesse sentido, dividimos nossa exposição em duas partes. Na primeira, ressaltamos, sobretudo, nuanças do impacto das invasões nas cidades, valorizando nesse propósito o relato do bispo Idácio de Chaves. $\mathrm{Na}$ segunda, sublinhamos particularmente alguns dos elementos capazes de revelar a ampliação da influência dos bispos na vida urbana nos séculos VI e VII.
\end{abstract}

do Rio de Janeiro.

Professora de História Medieval do Departamento de História da Universidade Federal 


\section{RESUMÉ}

Les Actes du Concile d'Elvira - qui a eu lieu au début du Ve siècle - nous donnent des indices révélateurs du processus d'expansion du christianisme hispanique et de son rapport étroit avec les centres urbains. À partir de la lecture et de l'analyse de ces actes, nous pouvons inférer une activité religieuse régulière dans dix-neuf villes qui ont toutes envoyé des représentants à ce concile. Malgré tous les revers, après trois siècles nous pouvons toujours observer ce processus. Au VIIe siècle, on retrouve un haut clergé très influent, dont les actions conditionnaient une grande partie de la vitalité urbaine. Ainsi, si les invasions germaniques du Ve siècle ont causé une importante désorganisation des institutions péninsulaires, cela n'a pas impliqué la perte d'influence des ecclésiastiques dans la direction des centres urbains pendant les siècles ultérieurs. Plus tard, quand les germains se sont établis et ont organisé des royaumes, l'action de l'élite cléricale a été sentie autant dans les domaines religieux que civils.Cet article se propose donc d'analyser quelques aspects de l'insertion de l'évêché hispanique dans les centres urbains du Ve au VIIe siècle. Pour cela, nous avons partagé ce travail en deux parties. D'abord, nous avons mis en avant les nuances qui doivent être faites à propos de l'impact des invasions sur les villes, en prenant en considération le témoin de l'évêque Hydace de Chaves. Ensuite, nous avons mis l'accent sur quelques éléments qui peuvent dévoiler l'augmentation de l'influence des évêques sur la vie urbaine aux VIe et VIIe siècles.

\section{Introdução}

As atas do Concílio de Elvira, realizado em princípios do século IV, fornecem-nos indícios significativos do processo de expansão do cristianismo na Península Hispânica e sua estreita relação com os centros urbanos. Da leitura e análise de tais atas, uma atividade religiosa regular pode ser deduzida em 19 cidades, entre as quais estão Córdoba, Hispalis, Mérida, Zaragoza, Toledo, Braga, León, Málaga, Tucci, Acci, Urci, Ossonova, cujos representantes participaram do referido concílio. ${ }^{1}$ Malgrado todos os reve-

1 VIVES, J. (Ed.). Concilios visigóticos e hispano-romanos. Madrid: CSIC. Instituto Enrique Florez, 1963. p. 1. 
ses, passados três séculos, observamos a continuidade daquele processo. Deparamo-nos, então, com um alto clero extremamente influente, cujas ações norteiam grande parte do que restara da vitalidade urbana.

Dessa forma, embora as invasões germânicas do século $\mathrm{V}$ tenham promovido uma considerável desorganização das instituições peninsulares, fenômeno, em um primeiro momento, especialmente palpável nas cidades, isto não significou a perda de influência do segmento eclesiástico sobre os rumos dos centros urbanos nos séculos seguintes. Com o posterior assentamento dos germanos e a organização de reinos, a atuação de uma elite clerical se destacou não apenas na esfera religiosa, mas também na civil.

Interessa-nos, pois, neste artigo a análise de alguns aspectos da inserção do episcopado hispânico nos núcleos urbanos nos séculos V-VII. Nesse sentido, dividimos nossa exposição em duas partes centrais. Na primeira, ressaltamos, sobretudo, nuanças do impacto das invasões nas cidades, valorizando nesse propósito o relato do bispo Idácio de Chaves. $\mathrm{Na}$ segunda, sublinhamos particularmente alguns dos elementos capazes de revelar a ampliação da influência dos bispos na vida urbana nos séculos VI e VII.

\section{O impacto das invasões germânicas nos centros urbanos hispânicos}

A urbanização das áreas incorporadas pelo Império Romano constituiu parte fundamental do projeto de exploração e manutenção de tais áreas. Apesar desta política, as distintas origens históricas e a diferenciada inserção de cada província no contexto político-econômico do Império, entre outros aspectos, definiram a impossibilidade de um desenvolvimento citadino homogêneo. De qualquer modo, a despeito das peculiaridades locais, a relevância e a prosperidade da rede urbana instituída na Península Hispânica podem ser apontadas como certas até as invasões de francos e alamanos, no século III. O fenômeno urbano hispânico assumiu, a partir de 
então, uma nova configuração, ainda que não marcada necessariamente pelo colapso irremediável de todo o conjunto. ${ }^{2}$

Entre outros fatores, devido ao caráter transitório da presença de alamanos e francos em território peninsular, estas invasões não tiveram a mesma repercussão que as do século V. Mesmo assim colaboraram significativamente para a redução, consolidada com a construção de muralhas, do perímetro urbano em muitas cidades, entre as quais podemos mencionar Gerona, Barcino, Ilerda, Caesaraugusta, Cantabria, Emerita Augusta, Uxama, Caparra, Augustobriga, Palencia, Ager e Baelo. ${ }^{3}$ A movimentação de francos e alamanos pôde interferir tanto no processo de ruralização como na tendência à bipolarização da sociedade entre os que detinham o poder e os que nada, ou muito pouco, possuíam. ${ }^{4}$ Cabe ressaltar que os "poderosos", embora tenham, de forma significativa, buscado maior segurança em suas propriedades rurais, mantiveram sua influência sobre as cidades mais prósperas, especialmente aquelas do sul da Península.

Ainda que, em fins do século III e durante parte do IV, predominassem, no corpo eclesiástico hispânico, clérigos que vivessem modestamente, ${ }^{5}$ a partir de 313 , os bispos paulatinamente passaram a desfrutar de prerrogativas, concedidas pelos imperadores, que acabaram por tornar o cargo identificado aos segmentos privilegiados. ${ }^{6} \mathrm{Com}$ a liberação do exercício de

2 Mesmo que não tenha sido uma regra, as áreas com maior concentração urbana sofreram mais imediatamente com a chegada dos francos e alamanos. As partes meridionais da Hispania, em particular a Bética e o sul da Lusitânia, destacavam-se em relação às zonas do norte, noroeste e centro, menos urbanizadas. De qualquer modo, ainda que a exata trajetória feita por estes grupos seja de difícil reconstituição, sabe-se que os francos, em torno de 260, teriam atravessado o Pirineu Oriental e que uma segunda invasão ocorrera por volta de 276, desta vez, através de Navarra. Os vestígios arqueológicos das cidades saqueadas ratificam a certeza de que o percurso adotado pelos invasores nem sempre privilegiou a rota das mais importantes cidades. MONTENGRO, A. Evolución política de Hispania en el Bajo Imperio. In: BLÁZQUEZ, J. M. et al. Historia de España Antigua. Hispania Romana. Madrid: Cátedra, 1978. p. 493-494. v. 2.

3 BLÁZQUEZ, J. M. Historia social y economica. La España Romana (siglos III-V). Madrid: Confederación Española de Cajas de Ahorros, 1975. p. 33.

4 Tais grupos identificados, no Baixo Império, por honestiores e humiliores reúnem, cada um, vários segmentos. Buscando simplificadamente identificá-los, podemos afirmar que os honestiores detêm as riquezas e se apropriam do produto gerado pelo trabalho dos humiliores, habitantes do meio rural e urbano, cuja condição jurídica tende a se aproximar da categoria de semilivre. Cf. MONTENGRO, op. cit., p. 555 .

5 SOTOMAYOR Y MURO, M. La Iglesia en la España romana. In: GARCIA VILLOSLADA, R. (Dir.). Historia de la Iglesia en España. La Iglesia en la España romana y visigoda (siglos I-VIII). Madrid: BAC, 1979. p. 181.

6 A relativa diversidade de interesses no interior deste grupo não garantiu, a despeito do beneficiamento que a legislação conferiu ao episcopado, a aprovação incondicional de todas as nuanças da 
funções públicas, ${ }^{7}$ dedicado às obrigações eclesiásticas e respaldado para atuar como juiz das causas nas quais o clero estivesse envolvido, ${ }^{8}$ o bispo assumiu, na segunda metade do século IV, o título de defensor civitatis, ${ }^{9} \mathrm{o}$ que tornou inegavelmente as civitates o centro do seu poder.

Para a alta hierarquia eclesiástica, as perspectivas eram as melhores possíveis. O estreitamento do relacionamento com as autoridades romanas favorecia a ampliação do número de fiéis e o fortalecimento do cristianismo. Nesse empreendimento, as cidades, apesar da progressiva perda de importância no cenário político-econômico do período, ${ }^{10}$ podiam ocupar lugar de destaque como núcleos de irradiação da fé, considerando que muito ainda precisava ser feito acerca da cristianização no espaço rural cada vez mais influente. As invasões de vândalos, alanos e suevos, em 409, contudo, interromperam, ao menos temporariamente, a relativa tranqüilidade que desfrutava o episcopado e o segmento social ao qual se vinculava.

As invasões foram registradas por Idácio, bispo de Chaves e um típico representante das camadas sociais identificadas como privilegiadas. A sua crônica, ${ }^{11}$ cujas referências se estendem ao ano de 469 , evidencia, portanto, a perspectiva de um membro da elite local que se desesperava diante da possibilidade de destruição das bases do seu poder. $\mathrm{O}$ tom predo-

política imperial. Nesse sentido, as questões em torno do movimento priscilianista são emblemáticas, já que claramente evidenciaram uma elite nem sempre coesa. Neste episódio, uma parte da aristocracia local indicou descontentamento com a política imperial em curso se fazendo representar nas críticas, feitas por bispos identificados com Prisciliano, ao comportamento pouco ascético de alguns membros da cúpula eclesiástica, excessivamente comprometidos com os interesses de Roma. Outra parte da aristocracia, contudo, atuou no sentido de respaldar as perseguições aos priscilianistas, rotulados de heréticos, com a chancela imperial. Sobre o movimento priscilianista, cf., entre outros: CHADWICK, H. Prisciliano de Avila. Madrid: EspasaCalpe, 1978; BARBERO DE AGUILERA, A. El Priscilianismo: herejía o movimiento social? In: Conflictos y estructuras sociales en la Hispania Antigua. Madrid: Akal, 1977. p. 77-114, e CABRERA, J. Estudio sobre el Priscilianismo en la Galicia Antigua. Granada: Univesidad de Granada, 1983.

7 "Con el fin de que las organizaciones al servicio de la iglesia tengan socios numerosos, los clérigos y sus acólitos estarán exentos del pago de impuestos, y serán protegidos contra el cumplimiento de servicios obligatorios públicos de caráter manual...”. CÓDIGO Teodosiano, II, 10. In: GALLEGO BLANCO, E. Relaciones entre la Iglesia y el Estado en la Edad Media. Madrid: Revista de Occidente, 1973. p. 71.

8 "Los clérigos no deben ser acusados sino ante los bispos." CÓDIGO Teodosiano, II, 41. In: GALLEGO BLANCO, op. cit.

9 SOTOMAYOR Y MURO, op. cit., p. 177.

10 Cf. FRIGHETTO, R. Cultura e poder na Antigüidade Tardia Ocidental. Curitiba: Juruá, 2000. p. 63-123.

11 IDACIO. Crónica. Versão e anotações de José Cardoso. Braga: Universidade do Minho, 1982. p. 13. 
minante em seu relato foi de pessimismo, por um lado e de desprezo aos germanos, por outro. Assim, além das implacáveis depredações e chacinas, ${ }^{12}$ os germanos foram apresentados como traidores ${ }^{13}$ pelo bispo.

É bem provável que, ao vagarem por toda a Península por quase dois anos sem fixação, esses grupos tenham vivido exclusivamente do saque. ${ }^{14}$ A certeza de que provocaram pânico e destruição nas cidades e de que poucas foram as áreas que ficaram imunes às depredações, no entanto, precisa ser relativizada. Na verdade, tal quadro, como algo generalizado, não marcou a ação dos germanos por toda a região e nem por muito tempo. Salvo a exceção representada pelos vândalos, após o assentamento, só se praticou o saque aos centros urbanos como recurso expansionista ou em represálias a eventuais alianças feitas pelas elites citadinas com adversários do grupo germano que controlava a localidade.

A divisão da Península, em torno de 411, certamente resultado de algum tipo de acordo ${ }^{15}$ feito com as autoridades romanas e os invasores, garantiu aos mais fortes na ocasião os melhores territórios. Revela-nos o bispo Chaves que os vândalos asdingos ficaram com a Galécia; os suevos, com parte situada no extremo ocidental do mar Oceano; os alanos, com as províncias da Lusitânia e da Cartaginense e os vândalos silingos, com a Bética. ${ }^{16}$ Essa distribuição, entretanto, não chegou sequer a completar uma década, já que um pacto ${ }^{17}$ entre Valia, rei dos visigodos, federados romanos, e o Império promoveu a eliminação dos alanos e vândalos silingos. Após tal extermínio, os vândalos asdingos abandonaram o noroeste aos suevos e se estabeleceram na Bética, até 429, momento em que deixaram definitivamente a Península. ${ }^{18}$ A curta permanência dos vândalos asdingos na região apenas 20 anos - não foi suficiente, contudo, para diminuir a importância da

12 IDACIO, op. cit., p. 13.

13 Ibid., p. 21.

14 ORLANDIS, J. Historia de España. La España visigótica. Madrid: Gredos, 1977. p. 24.

15 A maioria dos autores defende a existência de algum tipo de acordo entre o Império e os invasores peninsulares na base de um "foedus", ou algo próximo, que implicasse o reconhecimento da autoridade do primeiro. Entre outros, cf.: VILLARES, R. História da Galiza. Lisboa: Horizonte, 1991. p. 47; AVILÉS FERNÁNDEZ, M. La España visigoda. Madrid: Edaf, 1980. p. 26; ORLANDIS, op. cit. Defendendo a inexistência de acordos do tipo acima, cf., entre outros: DÍAZ MARTÍNEZ, P. C. La modalidad del asentamiento suevo y sus consecuencias. Studia Zamorensia Historica, n. 7, p. 353-365, 1986.

16 IDÁCIO, op. cit., p. 13.

17 ORLANDIS, J. Historia del reino visigodo Español. Madrid: Rialp, 1988. p. $26-28$.

18 Os vândalos se dirigiram para o norte da África, onde organizaram um reino. 
sua ação depredatória. A instabilidade com a qual se deu o assentamento deste grupo refletiu-se em contínuos saques nas zonas hispânicas meridionais. Até mesmo importantes cidades como Cartagena e Sevilha, ${ }^{19}$ apesar de amuralhadas, não resistiram a suas investidas.

Os relatos de saques a núcleos urbanos se avolumam na Crônica de Idácio. Além dos vândalos, visigodos e suevos teriam atuado nesse sentido. Estes últimos são acusados de romperem, com freqüência, os acordos feitos com as autoridades citadinas da Galécia e Lusitânia ${ }^{20}$ e, como desdobramento, de invadirem importantes cidades, como Lisboa ${ }^{21} \mathrm{e}$ Conimbriga. ${ }^{22}$ Também a metade ocidental da Bética não foi por eles poupada quando buscaram ampliar seu raio de influência. Nesse empreendimento, além de Sevilha, ${ }^{23}$ saquearam, entre 440 e 450, Mérida, Lérida, Mértola e Zaragoza. ${ }^{24}$ Os visigodos, na qualidade de federados, apesar de inicialmente representarem os interesses do Império, igualmente não foram indulgentes com as cidades. Na verdade, utilizaram-se dessa prerrogativa para pilhar Braga, Astorga e Palência. ${ }^{25}$ Alegaram estar defendendo os direitos imperiais, já que tais cidades teriam apoiado opositores de Roma.

Sendo muitos dos centros urbanos saqueados, principalmente aqueles nos quais o poder ainda se mantinha em mãos das aristocracias locais, compreende-se não apenas a ênfase conferida por Idácio aos ataques às cidades, mas também as razões dos germanos. Tais cidades possuíam uma relativa autonomia política e se apresentavam, de certa maneira, como focos de resistência aos invasores, ao menos nos primeiros momentos. O próprio Idácio teria participado de uma missão com o objetivo de conseguir ajuda de generais romanos para conter as ações dos suevos na Galécia. ${ }^{26}$ Situações como essa certamente justificam parte do comportamento dos invasores

19 GARCÍA MORENO, L. Las invasiones y la época visigoda. Reinos y condados cristianos. In: TUÑÓN DE LARA, M. (Dir.). História de España. Romanismo y germanismo. El despertar de los pueblos hispánicos. Barcelona: Labor, 1981. p. 255.

20 IDACIO, op. cit., p. 21.

21 Ibid., p. 39.

22 Ibid., 241. II. p. 46. Cf., também: ISIDORO DE SEVILLA. Historia de los godos, Vándalos y suevos. Estudio, edición crítica y traducción de Cristobal Rodriguez Alonso. León: Caja de Ahorros y Monte de Piedad de León y El Archivo Histórico Diocesano de León, 1975. p. 317.

23 IDACIO, op. cit., 123. p. 26.

24 Ibid., 119. p. 25; 121. p. 25; 142. p. 29.

25 IDACIO, op. cit., 174; 186. p. 36 e 38.

26 Ibid., 96. p. 21. 
que buscavam impor sua autoridade; mas a atenção que dedicaram às cidades esteve, sobretudo, relacionada ao butim que poderiam oferecer. Por serem zonas que concentravam riquezas de fácil acesso, atraíram a cobiça dos invasores.

Devemos salientar, contudo, que as cidades jamais se constituíram como espaços privilegiados de assentamento para os invasores. O reduzido número de guerreiros em relação à população autóctone ${ }^{27}$ intimidava e promovia intranqüilidade. A proximidade foi o fator de interesse. As cidades amuralhadas podiam garantir a segurança em situação de embate com adversários a ela externos. As tropas militares ali poderiam dispor de uma certa proteção. Nesse sentido, há registros de que guarnições suevas se mantiveram em áreas como Braga e Mérida. ${ }^{28}$ É importante ressaltar, ainda, que para os germanos o desprestígio das cidades, como lugar de estabelecimento, estivera relacionado também à inexistência de uma tradição cultural associada à urbanidade entre tais grupos e, em decorrência, como destaca Foussier, ${ }^{29}$ ao fato de que as terras incultas lhes eram mais atrativas pela importância que atribuíam à criação de gado.

Ao que tudo indica, as dificuldades no relacionamento entre a população hispano-romana e suevos e visigodos ${ }^{30}$ não tardaram a ser superadas e acabaram por, em suas expressões mais amplas, caracterizar apenas as primeiras décadas após o assentamento. Até porque não podemos imaginar invasores que desejassem indefinidamente praticar o saque e depredar as mais variadas regiões; ${ }^{31}$ os recursos ali existentes não eram infinitos, e não haveria o menor sentido em tal opção, já que suevos e visigodos organizaram reinos cuja prosperidade, documentada, não poderia ter se tornado viável sem a participação dos segmentos autóctones.

27 Segundo Garcia Moreno, o número total de integrantes dos três grupos não excedia 200 mil e o número de guerreiros girava em torno de 56 mil. Os germanos não chegavam a representar, portanto, 5\% do número total de habitantes da Península. Cf. GARCÍA MORENO, Las invasiones..., op. cit., p. 251.

28 PINTO, S. da S. Requiário de Braga. O primeiro rei católico do Orbe Latino. Bracara Augusta, Braga, v. 5, p. 44-60, 1954.

29 FOUSSIER, R. La Edad Media. La formación del mundo medieval 350-950. Barcelona: Critica, 1988. v. 1. p. 106.

30 Após 429, não há outros grupos germanos na Península.

31 De uma maneira geral, segundo Malcolm Todd, os germanos não objetivaram, mesmo nos séculos anteriores às invasões, uma prática exclusivamente depredatória. Cf.: TODD, M. Les Germains. Aux frontières de l'empire romain Paris: Armand Colin, 1990. p. 143. 


\section{A inserção do clero na vida urbana hispânica nos séculos VI e VII}

Após o impacto das invasões, já com os reinos estabelecidos, ainda que a sociedade se caracterizasse predominantemente como rural, tendo a maioria das cidades perdido relevância, alguns centros urbanos, como Mérida, Évora, Tarragona e Barcelona, tornaram-se importantes. ${ }^{32}$ Constatamos também que, a partir do século VI, parte da aristocracia provincial que optou por não privilegiar as cidades, no século anterior, não tardou a voltar e reassumir algumas das suas funções. Evidentemente, pautou-se em uma nova correlação de forças que agora contava com os grupos germanos como elemento mais forte. Em regiões como a Bética, o dinamismo comercial dos núcleos urbanos jamais foi completamente paralisado, configurando-se permanente atrativo para a aristocracia hispano-romana. Na verdade, como já mencionamos anteriormente, a presença de tal aristocracia no sul da Península é um dado mesmo no momento das invasões do século III. A elite autóctone esteve marcadamente ativa, portanto, em locais importantes como Sevilha, Córdoba, Écija, Mérida, Calahorra, Lérida. Também em Lugo e Toledo, principais centros administrativos da Península, as aristocracias estiveram em evidência.

Assim como já verificado no século $\mathrm{V}$, ao observarmos a participação desses segmentos na vida urbana, sobressai-se a sua vinculação às atividades eclesiásticas. ${ }^{33}$ As funções episcopais continuaram sendo exercidas, via de regra, por membros oriundos de tais segmentos. A despeito de perseguições pontuais realizadas por suevos e visigodos, antes da conversão de ambos,${ }^{34}$ o prestígio do cristianismo junto às populações urbanas e a estabilidade das estruturas eclesiásticas garantiram, a médio prazo, sua vitalidade e a influência dos religiosos, de um modo geral, e do episcopado, em especial, sobre a sociedade. Logo, o âmbito eclesiástico permaneceu como esfera de atuação das elites autóctones.

32 FOUSSIER, op. cit., p. 95.

33 A participação em postos-chave da administração aparece como outra relevante atividade das aristocracias fundiárias. Cf. GARCIA MORENO, L. Historia de España visigoda. Madrid: Catedra, 1989. p. 266-268.

34 Os suevos se converteram ao cristianismo, em sua versão ortodoxa, em torno de 550 e os visigodos, em 589. 
A escassez de fontes não nos permite acompanhar detalhes da manifestação do poder episcopal, nas cidades existentes no perímetro do reino suevo, ao longo do século $\mathrm{V}$ e grande parte do VI. Com o fim da Crônica de Idácio, em 469, só voltamos a dispor de fontes para a análise desta questão nos anos imediatamente anteriores à incorporação do reino suevo ao visigodo, em 585. Os registros da destacada atuação do bispo de Braga, entre os anos de 561 e 580, embora ratifiquem a influência episcopal exercida sobre a sociedade, ${ }^{35}$ são insuficientes para a perspectiva de continuidade que adotamos em nossa abordagem. Assim, priorizamos o reino visigodo após 585, identificado totalmente, do ponto de vista territorial, com a Península Hispânica.

Alguns expedientes, sobre os quais nos debruçaremos a seguir, contribuíram particularmente para a ampliação do poder episcopal nas cidades visigodas: o controle dos núcleos de saber e o favorecimento monárquico. Este último suscitou uma série de desdobramentos entre os quais nos interessa, dado o objetivo deste artigo, destacar, sobretudo, os vinculados ao que nomeamos assistência material e assistência jurídica.

As escolas episcopais hispânicas se constituíram importante fonte de prestígio para os bispos. ${ }^{36}$ Como locais de formação, ainda que em geral um pouco menos conceituadas que as escolas monásticas, eram, com estas últimas, as únicas capacitadas a fornecer educação superior aos clérigos. A escola episcopal ficava sob inteira responsabilidade do bispo. Sua sede e, com frequiência, parte de sua residência, era o lugar de funcionamento de tais núcleos de formação.

O anúncio da criação da escola episcopal na Península Ibérica remonta ao século VI e consta de deliberação conciliar. ${ }^{37}$ Foi o empenho de

35 Cf., entre outros, GIGANTE, J. A. M. Ambiente e significado da Legislação do Concílio de Braga. In: SEMANA INTERNACIONAL DE DIREITO CANÔNICO - O Concílio de Braga e a Função da Legislação Particular da Igreja, 14., 1975, Braga. Atas... Braga, 1975. p. 13-31; GOMES, M. J. da S. S. Martinho de Dume: a sua ação litúrgico-pastoral. In: CENTENÁRIO DE DEDICAÇÃO DA SÉ DE BRAGA. Congresso Internacional, 9., 1990, Braga. Actas... Braga, 1990. v. 3. p. 157-166, e FERREIRO, A. Braga and Tours: some observations on Gregory 's De virtutibus sancti Martini (1.11). Journal of Early Christian Studies, v. 3, n. 2, p.195-210, 1995.

36 Sobre as escolas episcopais peninsulares, cf., entre outros: FERNÁNDEZ ALONSO, J. La cura pastoral en la España romanovisigoda. Roma: Instituto Español de Estudios Eclesiásticos, 1955. p. 77-79; 104-109 e RICHÉ, P. Éducation et culture dan l'occident barbare VI ${ }^{e}$-VIII ${ }^{e}$ siécles. Paris: Seuil, 1962. p. $166-169$.

37 Concilio de Toledo II. In: VIVES, op. cit., can. I. p. 42. 
bispos renomados como Isidoro de Sevilha, entretanto, que deu dinamismo ao projeto. Como parte desse empenho, há a inserção de tais escolas na intensa atividade cultural empreendida no século VII, que, como uma de suas facetas, valorizou a educação humanística clássica. A inexistência de escolas laicas aumentava a importância das religiosas. Os professores particulares que atendiam à elite, até mesmo membros da nobreza germânica, eram todos clérigos, inclusive bispos, e, em sua maioria, eram formados em tais escolas. Lembremos, por exemplo, que Isidoro foi professor de Sisebudo e Sisenando, dois monarcas de princípios do século VII. ${ }^{38}$

Ainda que o afluxo de estudantes fosse restrito a tais escolas, devido a uma série de razões, como, por exemplo, o seu caráter de centros de formação clerical, sua importância não pode ser desconsiderada. Entre outros pontos que destacam o seu valor como fomentadoras do poder episcopal, verificamos que o acesso às sete artes liberais, além dos demais conhecimentos ali adquiridos, capacitavam o religioso não apenas ao exercício clerical, mas também à ocupação de cargos na administração civil. O respeito à hierarquia eclesiástica garantia aos bispos a possibilidade de influência direta sobre funcionários da estrutura de poder visigoda.

Mérida, Palência, Toledo, Sevilha, Zaragoza possuíram as mais conceituadas escolas episcopais da Península durante o período, usufruindo as duas últimas, inclusive, de importantes bibliotecas. Todas, sem exceção, contaram com o zêlo redobrado de bispos cujos nomes são, por um lado, referência direta à produção cultural do período e, por outro, ao sucesso de tais núcleos de estudos. Assim, os vínculos de Paulo e Fidel à escola de Mérida, de Leandro e Isidoro à de Sevilha, de Braulio à de Zaragoza, de Frutuoso à Palência, de Ildefonso à Toledo, entre outros, ratificam o importante papel destes centros. Constatamos que, numa relação de reciprocidade, seus bispos conferiram prestígio a tais escolas e estas foram espaços, também, de estímulo à reprodução do poder episcopal.

O início de uma política de favorecimento aos bispos possui relação com um momento imediatamente posterior à conversão, em 589, do monarca visigodo Recaredo. $\mathrm{O}$ abandono do arianismo, decisão diretamente relacionada à paulatina fusão de interesses entre a elite autóctone e as autoridades germânicas, não passou, portanto, distante da atividade epis-

38 QUILES, I. San Isidoro de Sevilla. Madrid: Espasa-Calpe, 1965. p. 36 e 39. 
copal. Além da crescente participação de integrantes da nobreza germânica na alta hierarquia eclesiástica, ${ }^{39}$ a partir do século VI, privilégios inerentes ao poder episcopal foram ratificados e ampliados pelos monarcas germanos que encontraram na cúpula episcopal os mais qualificados colaboradores no processo de legitimação de seus governos.

Embora se observe a crescente preocupação no seio da elite religiosa com o fortalecimento da autoridade episcopal junto aos seus subordinados, estivessem eles no campo ou não, ${ }^{40}$ a cidade se manteve como centro do seu poder. Nela a autoridade do bispo se tornou cada vez mais evidente com o apoio dos monarcas e o respaldo da legislação real. Tal legislação reconhecia, por exemplo, a responsabilidade da Igreja quanto à assistência das populações carentes ${ }^{41}$ expressivamente representadas nos espaços urbanos, e revalidava as prerrogativas episcopais jurídicas de caráter religioso, além de outorgar-lhe também competência civil.

A ação da Igreja como protetora dos pobres não resulta evidentemente de uma inovadora atribuição conferida pelos monarcas visigodos. Contudo, o reconhecimento desta prática assistencial por Recesvinto, ${ }^{42}$ ao tornar lei uma proposição do IV Concílio de Toledo, ${ }^{43}$ que sublinha o papel do bispo nesta função, legitima a responsabilidade de tal membro da hierarquia clerical sobre uma parcela significativa de habitantes da cidade.

Garcia Moreno, ao discorrer sobre os segmentos que compunham a sociedade visigoda, chama a atenção para o altíssimo número de servos fugidos, mendigos, enfermos e todo o tipo de marginal presente nos núcleos urbanos. ${ }^{44}$ Tal quadro, ainda segundo este autor, estaria justificado pela baixa produtividade do solo, pesadas cargas fiscais e crescentes exigências senhoriais que tornavam as economias camponesas excessivamente vulne-

39 Frutuoso, bispo que já mencionamos em associação à prosperidade da escola de Palência, era parente direto do monarca. Cf. DIAZ Y DIAZ, M. C. Notas para uma cronología de Frutuoso de Braga. Bracara Augusta, Braga, v. 21, p. 215-223, 1967.

40 Cf., entre outros: Concilio de Toledo III. can. XIII. p. 129; Concilio de Toledo IV. can. XXXVI. p. 205; Concilio de Mérida. can. XI. p. 333, can. XIII. p. 334, can. XVII. p. 337. In: VIVES. op. cit.

41 ORLANDIS, J. La asistencia a los pobres en la Iglesia visigótica. In: JORNADAS LUSOESPANHOLAS DE HISTÓRIA MEDIEVAL - A pobreza e a assistência aos pobres na Península Ibérica durante a Idade Média, 1, 1972, Lisboa. Actas ... Lisboa, 1973. T. 2, p. 699-714. p. 700.

42 HOMET, R. La asistencia social en la España Medieval, su encuadramiento jurídico. Res Gesta, n. 27-28, p. 5-6, ene./dec. 1990.

43 IV Concilio de Toledo. In: Concilios Visigóticos e Hispano-Romanos. op. cit., can. XXXII. p. 204.

44 GARCIA MORENO, Historia de... op. cit., p. 285. 
ráveis às intempéries e pragas e acabavam por transformar as cidades em pólos de atração. ${ }^{45}$

A delimitação do perfil de pobre, entretanto, pode ser muito mais ampla do que a anteriormente indicada, não se restringindo aos pedintes. José Orlandis ressalta, em artigo dedicado à temática, ${ }^{46}$ a hipótese, bastante provável, de que os pauperes, destacados na legislação, devem ser identificados em oposição aos potentes, membros da aristocracia laica e eclesiástica ${ }^{47}$ Assim, no que se refere à assistência material prestada, ou seja, esmolas, abrigos e hospitais, os beneficiados estariam mais próximos do que hoje, conceitualmente, compreendemos como pobre, mas, no que concerne à assistência jurídica, o conjunto estaria mais ampliado e contemplaria todos os que não dispusessem dos mesmos recursos que as aristocracias.

As esmolas e demais benefícios concedidos aos necessitados provinham das doações de fiéis e dos recursos adquiridos com a administração do patrimônio eclesiástico. ${ }^{48}$ Cabe ressaltar que a regularidade com que os membros da Igreja, em particular os bispos, praticavam a doação de esmolas e demais caridades suscitou, entre as autoridades religiosas, a preocupação com a dilapidação dos bens desta instituição, sendo, pois, objeto de ampla legislação canônica, do que alguns cânones dos concílios de Toledo X $(656)^{49}$ e de Mérida (666) ${ }^{50}$ são os melhores exemplos. Buscava-se, dessa forma, conter a ânsia cristã de se praticar a caridade mas também coibir a excessiva ambição que eventualmente poderia nortear a ação de bispos que viam na prática assistencial a possibilidade de dilatação da sua popularidade, ambos estímulos danosos ao patrimônio eclesiástico.

Ainda no plano da assistência material, a construção e administração de hospitais e abrigos para os peregrinos nas cidades ${ }^{51}$ se tornara quase uma iniciativa exclusiva da Igreja. Apesar dos bispos nem sempre terem gerido recursos compatíveis com a manutenção de tais construções, cabe

45 GARCIA MORENO, Hi

46 ORLANDIS, J. La asistencia a los pobres en la Iglesia Visigótica. op. cit.

47 Cf. GARCÍA MORENO, Las invasiones ..., Reinos y condados cristianos. op. cit., p. 392-

402.

48 HOMET, op. cit., p. 6.

49 X Concilio de Toledo. In: VIVES. op. cit., p. 322-324. Cf. também GARCIA GALLO, A. El testamento de San Martin de Dumio. Bracara Augusta, Braga, v. 8, p. 36-44, 1957.

50 Concilio de Mérida. In: VIVES. op. cit., p. 325-343. Cf, em particular, o cânone XXI. p. 341.

51 FOSSIER, op. cit., p. 95. 
destacar a singularidade da experiência de Mérida, primeira cidade de onde se tem notícia da criação de um hospital na Península Ibérica. ${ }^{52}$ Tal hospital, erguido pelo bispo Masona, encontra-se registrado nas fontes pela qualidade dos seus médicos, pela limpeza das camas e pela comida ali servida. ${ }^{53}$ A propósito, a generosidade das esmolas e demais benefícios concedidos aos pobres em Mérida suscitaram o orgulho com que o autor anônimo ${ }^{54} \mathrm{da}$ obra Vitas Sanctorum Patrum Emeretensium se refere a esta cidade.

Quanto à assistência jurídica, anteriormente mencionada, devemos lembrar que, no que concerne às prerrogativas episcopais jurídicas de caráter religioso, os bispos já atuavam como juízes na Península, pelo menos desde o I Concílio de Toledo, em 400: ${ }^{55}$ isso sem mencionar a legislação imperial do século anterior. ${ }^{56}$ As penas que podiam impor, entretanto, só intimidavam a comunidade de fiéis, já que se referiam, nos casos mais graves, à excomunhão..$^{57}$

A indicação real para a ação de bispos em parceria com juízes seculares proporcionou, todavia, a ampliação da competência jurídica episcopal. ${ }^{58}$ Situações nas quais fiéis estivessem envolvidos, caracterizadas como faltas religiosas, poderiam ser apreciadas por um tribunal misto. Aqui, entre outras, estiveram questões relacionadas à idolatria e aos judeus. Como ilustração do grau de confusão existente neste momento entre as esferas religiosa e civil, observamos que uma pena imposta por um bispo no julgamento de matéria eclesiástica poderia implicar en benefício material para o poder civil. É o caso, por exemplo, de clérigos que, condenados, deveriam pagar multa à autoridade administrativa da cidade. ${ }^{59}$

Concretamente no que diz respeito à assistência jurídica a ser prestada aos pauperes, coube ao bispo, no uso das atribuições delegadas pelos

52 ORLANDIS, J. La vida en España en tiempo de los godos. Madrid: Rialp, 1991. p. 181.

53 Ibid., p. 182.

54 GROSSE, R. (Ed.). Las fuentes de la época visigoda y bizantinas. Barcelona: Bosch, 1947. p. 5 (Fontes Hispanae Antiquae, 9).

55 Concilio de Toledo I. In:VIVES. op. cit., can. XI. p. 22.

56 Cf. nota 8.

57 Em relação aos clérigos, o tribunal episcopal era naturalmente o adequado para qualquer questão e, neste caso, punições físicas eram relativamente comuns. As restrições a sua utilização presentes no III Concílio de Braga, em 675, indicam um certo abuso das autoridades. Cf. Concilio de Braga III. In: VIVES. op. cit., p. 370-379. can. VI. p. 377.

58 Cf. Concílio de Toledo III. In: VIVES. op. cit., can. XVII. p. 130.

59 Concílio de Narbona. In: VIVES. op. cit., can. IV. p. 147. 
monarcas e já previstas em cânones conciliares, ${ }^{60}$ proteger os pobres e, nesse sentido, intervir sempre que estivessem envolvidos em situações que claramente evidenciassem sua fragilidade. Apesar dos bispos não prescreverem diretamente penalidades mais rigorosas aos poderosos, as arbitrariedades e injustiças cometidas por estes poderiam ser denunciadas aos monarcas.

Em linhas gerais, no plano assistencial, os bispos nas cidades tinham a incumbência de proteger, alimentar e abrigar as populações fragilizadas, funções que, a despeito de toda a carga moral e religiosa que pudessem possuir, inegavelmente garantiam-lhes prestígio não só entre os amparados, mas também junto aos grupos poderosos, dos quais, não nos esqueçamos, eram parte integrante.

\section{Conclusão}

Ao finalizarmos, verificamos que, apesar das vicissitudes que o cristianismo enfrentou na Península Hispânica, no período compreendido entre os séculos IV e VII, sua presença nos centros urbanos foi marcada por uma crescente atividade. Como parte deste processo, o episcopado pôde ampliar sua influência sobre a sociedade ao longo dos séculos. Excetuando algumas décadas nas quais, após as invasões germânicas, do século $\mathrm{V}$, as cidades foram objeto de saques e depredações, o poder desfrutado pelos bispos pôde ser caracterizado pela continuidade e pela ampliação. De Idácio a Isidoro tal tendência está atestada.

Relacionado a esta continuidade esteve o fato de que os bispos provinham das aristocracias fundiárias, segmentos que, embora tenham precisado se associar à nobreza germânica, após a organização dos reinos bárbaros, representavam a elite socioeconômica da região. A tendência inicial de abandono dos centros urbanos por tais grupos, logo após chegada dos germanos, refluiu, portanto, tão logo o núcleo administrativo se definiu e os interesses puderam convergir. Tal convergência, expressão da mútua

60 Concílio de Toledo IV. In: VIVES, op. cit., can. XXII. p. 204. 
cooptação, possibilitou o estabelecimento de uma nova ordem dentro da qual foi possível a manutenção de grande parte dos privilégios da elite autóctone e a consolidação do poder dos conquistadores germânicos.

Nessa perspectiva, os monarcas visigodos, após a conversão, agiram no sentido de ratificar e alargar os poderes episcopais, particularmente revelados no âmbito das cidades. Elevando deliberações conciliares à categoria de lei, favoreceram, em troca de apoio à legitimação de sua autoridade em todo o reino, a atuação da alta hierarquia eclesiástica não apenas na esfera religiosa, mas também na civil.

Assim, além das obrigações pastorais referentes à diocese e a todo o clero a eles subordinados, constatamos a ação dos bispos em variadas frentes. Nestas, o episcopado soube garantir a expansão de sua influência com a criação de escolas, com a autoridade exercida sobre clérigos em funções administrativas e com a prática da assistência material e jurídica às populações urbanas necessitadas.

\section{Referências}

Fontes primárias:

CÓDIGO Teodosiano, II, 10. In: GALLEGO BLANCO, E. Relaciones entre la Iglesia y el Estado en la Edad Media. Madrid: Revista de Occidente, 1973.

IDACIO. Crónica. Versão e anotações de José Cardoso. Braga: Universidade do Minho, 1982.

ISIDORO DE SEVILLA. Historia de los godos, vándalos y suevos. Estudio, edición crítica y traducción de Cristobal Rodriguez Alonso. León: Caja de Ahorros y Monte de Piedad de León y El Archivo Histórico Diocesano de León, 1975.

VIVES, J. (Ed.). Concilios visigóticos e hispano-romanos. Madrid: CSIC. Instituto Enrique Florez, 1963. 
Fontes secundárias:

AVILÉS FERNÁNDEZ, M. La España visigoda. Madrid: Edaf, 1980.

BARBERO DE AGUILERA, A. El Priscilianismo: herejía o movimiento social? In: 1977. . Conflictos y estructuras sociales en la Hispania Antigua. Madrid: Akal,

BLÁZQUEZ, J. M. Historia social y económica. La España romana (siglos III-V). Madrid: Confederación Española de Cajas de Ahorros, 1975.

CABRERA, J. Estudio sobre el Priscilianismo en la Galicia Antigua. Granada: Univesidad de Granada, 1983.

CHADWICK, H. Prisciliano de Avila. Madrid: Espasa-Calpe, 1978.

DÍAZ MARTÍNEZ, P. C. La modalidad del asentamiento suevo y sus consecuencias. Studia Zamorensia Historica, n. 7, p. 353-365, 1986.

DIAZ Y DIAZ, M. C. Notas para uma cronología de Frutuoso de Braga. Bracara Augusta, Braga, v. 21, p. 215-223, 1967.

FERNÁNDEZ ALONSO, J. La cura pastoral en la España romanovisigoda. Roma: Instituto Español de Estudios Eclesiásticos, 1955.

FERREIRO, A. Braga and Tours: Some Observations on Gregory's De virtutibus sancti Martini. Journal of Early Christian Studies, v. 3, n. 2, p. 195-210, 1995.

FOUSSIER, R. La Edad Media. La formación del mundo medieval 350-950. Barcelona: Critica, 1988. v. 1.

FRIGHETTO, R. Cultura e poder na Antigüidade Tardia ocidental. Curitiba: Juruá, 2000.

GARCIA GALLO, A. El testamento de San Martin de Dumio. Bracara Augusta, Braga, v. 8, p. 36-44, 1957.

GARCIA MORENO, L. Las Invasiones y la época visigoda. Reinos y condados cristianos. In: TUÑÓN DE LARA, M. (Dir.). História de España. Romanismo y germanismo. El despertar de los pueblos hispánicos. Barcelona: Labor, 1981.

. Historia de España visigoda. Madrid: Cátedra, 1989.

GIGANTE, J. A. M. Ambiente e Significado da Legislação do Concílio de Braga. In: SEMANA INTERNACIONAL DE DIREITO CANÔNICO - O CONCÍLIO DE BRAGA E A FUNÇÃO DA LEGISLAÇÃO PARTICULAR DA IGREJA, 14. 1975, Braga. Atas... Braga, 1975. p. 13-31. 
GOMES, M. J. da S. S. Martinho de Dume: a sua ação litúrgico-pastoral. In: CENTENÁRIO DE DEDICAÇÃO DA SÉ DE BRAGA. CONGRESSO INTERNACIONAL, 9., 1990, Braga. Actas... Braga, 1990. v. 3, p. 157-166.

GROSSE, R. (Ed.). Las fuentes de la época visigoda y bizantinas. Barcelona: Bosch, 1947. (Fontes Hispanae Antiquae, 9).

HOMET, R. La asistencia social en la España Medieval, su encuadramiento jurídico. Res Gesta, n. 27-28, p. 5-6, ene./dec. 1990.

MONTENGRO, A. Evolución política de hispania en el Bajo Imperio. In: BLÁZQUEZ, J. M et al. Historia de España Antigua. Hispania Romana. Madrid: Cátedra, 1978. v. 2.

ORLANDIS, J. Historia del reino visigodo Español. Madrid: Rialp, 1988.

La asistencia a los pobres en la Iglesia visigótica. In: JORNADAS LUSOESPANHOLAS DE HISTÓRIA MEDIEVAL - A POBREZA E A ASSISTÊNCIA AOS POBRES NA PENÍNSULA IBÉRICA DURANTE A IDADE MÉDIA, 1., 1972, Lisboa. Actas... Lisboa, 1973. t. 2, p. 699-714.

. Historia de España. La España visigótica. Madrid: Gredos, 1977.

. La vida en España en tiempo de los godos. Madrid: Rialp, 1991. p. 181.

PINTO, S. da S. Requiário de Braga. O Primeiro Rei Católico do Orbe Latino. Bracara Augusta, Braga, v. 5, p. 44-60, 1954.

QUILES, I. San Isidoro de Sevilla. Madrid: Espasa-Calpe, 1965.

RICHÉ, P. Éducation et culture dan l'occident barbare VI ${ }^{e}$-VIII' siécles. Paris: Seuil, 1962.

SOTOMAYOR Y MURO, M. La Iglesia en la España Romana. In: GARCIA VILLOSLADA, R. (Dir.). Historia de la Iglesia en España. La Iglesia en la España romana y Visigoda (siglos I-VIII). Madrid: BAC, 1979.

TODD, M. Les Germains. Aux frontières de l'empire romain. Paris: Armand Colin, 1990.

VILLARES, R. História da Galiza. Lisboa: Horizonte, 1991. 